\title{
Autocures en el pacient crònic, el paper de l'equip d'atenció primària: presa de decisions compartida
}

\author{
Concepción CARratalá (maria.carratala@umh.es) \\ Domingo Orozco (dorozco@umh.es) \\ Universitat Miguel Hernández
}

\section{Introducció}

\subsection{Aspectes demogràfics de la cronicitat a Espanya}

Segons les dades de la projecció de població a llarg termini elaborada per l'Institut Nacional d'Estadística (INE) (Ferrer i altres, 2012), les tendències demogràfiques actuals portarien a una reducció progressiva del creixement poblacional en les properes dècades: el creixement natural de la població es faria negatiu des de 2020 i la població major de 64 anys es duplicaria en 40 anys, i passaria a constituir el 31,9\% de la població total de l'any 2049. És previsible que el nivell d'envelliment siga màxim en 2050.

En les consultes d'atenció primària de la salut, fins al $40 \%$ dels pacients multimòrbids presenten tres o més malalties cròniques (Gràfica 1), el 94\% està polimedicat (pren més de dos o tres medicaments), i el 37\% manifesta deteriorament cognitiu. La prevalença de multimorbiditat es pot estimar en un 1,38\% de la població general o un 5\% en majors de 65 anys d'edat.

A Espanya, les dones representen el 76,3\% de les persones identificades com a cuidadores principals de persones dependents. El perfil de persona cuidadora principal és una dona entre 45 i 64 anys, que resideix en la mateixa llar que la persona a qui presta cures. La persona que fonamentalment cuida dels hòmens majors amb dependència és la seua cònjuge seguida de la seua filla. En el cas de les dones majors que necessiten ajuda, són les filles les que fonamentalment es fan càrrec de les cures, seguides d'altres familiars i amics. Les persones que presten cures manifesten que tenen dificultats per a exercir les seues tasques i es veuen afectades en la seua salut i en la seua vida personal (Ferrer i altres, 2012).

\subsection{El paper dels professionals d'atenció primària en el model de cronicitat}

Es fa necessari potenciar el paper dels professionals de medicina i infermeria d'atenció primària $(\mathrm{AP}) \mathrm{com}$ a referents dels pacients amb problemes crònics de salut per al seguiment dels seus processos i l'activació de recursos. Per això és important enfortir els equips d'atenció primària (EAP) i reorganitzar l'atenció. La implicació dels pacients en l'atenció de la salut d'ells mateixos hauria de ser un aspecte rellevant i comú de tot tipus d'intervencions (Ferrer i altres, 2012). 
En relació a aquesta reorganització de les cures, és bàsic establir una estratificació de la població que permeta identificar les persones amb risc d'emmalaltir i predir les necessitats de les persones que ja presenten malaltia crònica per tal d'optimitzar els programes de prevenció i d'atenció (González i altres, 2002).

Un dels aspectes rellevants en el model de cronicitat és millorar la comunicació amb les persones, personalitzar el tracte i humanitzar les cures, aspectes que han de ser el fil conductor en totes les intervencions destinades a millorar l'abordatge de la cronicitat. Per això s'han posat en marxa diferents models d'organització (Orem, 2015, Bengoa i altres, 2009) i de treball en equip on participen tots els integrants del procés, com es pot veure en l'esquema següent:

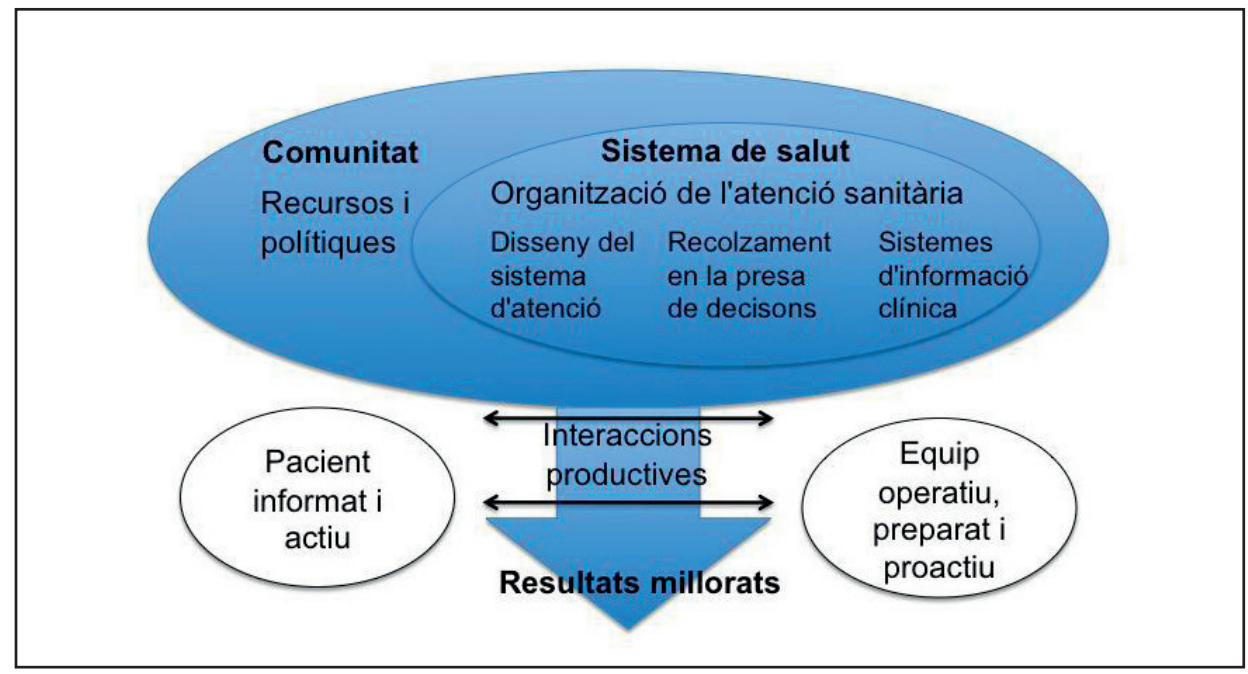

Esquema 1. Model de cronicitat basat en el Chronic Care Model del Programa ICIC (Improving Chronic Illness Care), de l'Institut MacColl de Seattle (EUA), modificat de: <www.improvingchroniccare.org $>$.

\section{Model de cronicitat}

L'augment de les malalties cròniques, motivat per l'envelliment progressiu de la població, ha conduït a la cerca de noves fórmules en la gestió del sistema de salut en diferents països, entre els quals es troba el nostre, i ha donat lloc a un nou enfocament en l'exercici de l'activitat diària dels professionals sanitaris des de l'àmbit hospitalari i en atenció primària. Actualment, ens trobem en un context social en què els pacients cada dia tenen un major accés a la informació i una major capacitat de decidir per ells mateixos. Aquesta realitat està canviant la relació professional-pacient. L'actitud passiva del rol del pacient (vocable que procedeix del llatí patients,-entis, que significa com a verb patir, doldre, i com a qualificatiu que té paciència o persona pacient) s'està modificant per a passar a ser copartícip en la presa de decisions sobre la seua salut i la seua malaltia. Fins i tot l'Organització Mundial de la Salut (OMS) (Ferrer i altres, 2012) recomana l'educació en l'autocura per a prevenir i tractar les malalties cròniques. 
A la Comunitat Valenciana, i dins del 3r Pla de Salut (2010-2013), figura específicament l'abordatge de les patologies cròniques i es remarca el paper del pacient i l'ús de noves tecnologies per al seu maneig. En concret, el Pla d'atenció a pacients amb malalties cròniques de la Comunitat Valenciana ${ }^{1}$ de 2012 té com a objectiu principal «proporcionar una atenció integral de qualitat, eficient i eficaç, a fi de reduir les conseqüències de la malaltia i la dependència en els pacients amb problemes de salut crònics, mitjançant la prestació de serveis adequats en cada moment, i aconseguir resultats millors en salut, més satisfacció davant de l'atenció socioassistencial i una qualitat de vida millor».

Dins del mateix Pla de Salut, el que acabem d'esmentar ha generat el desenvolupament del Projecte Valcrònic, l'objectiu del qual és gestionar adequadament l'atenció dels pacients amb malalties cròniques mitjançant una solució de telemedicina que permet el seguiment i l'atenció continuada d'aquests pacients. Aquest programa, en els seus inicis, s'ha centrat en quatre patologies cròniques: diabetis mellitus tipus 2 , la malaltia pulmonar obstructiva crònica (EPOC), la insuficiència cardíaca i la hipertensió arterial, així com la combinació d'aquestes malalties en el pacient pluripatològic.

\subsection{El pacient ha canviat}

El pacient actual amb malaltia crònica respon a un perfil diferent del d'èpoques anteriors pels motius següents (Bengoa i altres, 2009):

- És habitual un perfil de pacient crònic amb dues o tres malalties alhora (per exemple, diabetis mellitus, hipertensió i obesitat).

- És més actiu i espera participar en les decisions sobre el tractament amb el seu equip de professionals de salut.

- Espera cures i una bona gestió de la seua malaltia.

- Acudeix a les consultes de medicina i infermeria amb moltes preguntes i més coneixement sobre la seua malaltia.

- Utilitza les noves tecnologies (Internet, telèfon mòbil) activament per a completar les consultes amb l'equip sanitari.

- Espera continuïtat i seguretat en l'atenció en tot el sistema sociosanitari.

És evident que aquest és el repte del segle XXI en el sector sanitari. És un repte considerable, però hi ha bones perspectives si s'inicien els canvis necessaris en tot l'àmbit sociosanitari.

A Espanya, en pràcticament totes les autonomies, s'estan aplicant els nous enfocaments o models en gestió de la malaltia crònica que es caracteritzen per un «nou model de cures cròniques» (Ferrer i altres, 2012) que promou el suport en l'autoatenció, perquè fa que el pacient:

- Se senta el principal responsable de la seua salut.

- Aprenga a suportar millor la seua malaltia.

- Vulga i sàpiga adquirir i mantenir hàbits saludables.

- Confie a trobar-se millor siga quina siga la gravetat de la seua malaltia.

\footnotetext{
${ }^{1}<$ http://iv.congresocronicos.org/documentos/plan-de-atencion-pacientes-cronicos-valencia.pdf $>$.
} 
L'educació en autocura es diferencia de l'educació sanitària tradicional, la qual es limita a facilitar informació sanitària de forma oral o escrita. Per tant, ens trobem davant d'un enfocament diferent.

\subsection{Concepte de cura i autocura}

L'atenció personal o autocura juga un paper essencial en la gestió de les malalties cròniques. Per aquesta raó, és crucial reforçar l'autonomia del pacient i el suport a la formació, perquè els malalts puguen assumir un major control i responsabilitat de la seua malaltia. El pacient expert és aquella persona afectada per una malaltia crònica que és capaç de responsabilitzar-se de la seua pròpia malaltia i autocuidar-se sabent identificar els símptomes, mitjançant l'adquisició de la capacitat per a evitar-los i el desenvolupament d'habilitats per a gestionar l'impacte físic, emocional i social de la patologia, tot millorant així la seua qualitat de vida.

\subsubsection{Les autocures}

La paraula autocura està formada per dos vocables: auto (del grec avizo) que significa propi o per un mateix i per cura (del llatí pensara, cogitātus) que significa pensar, pensament, «sol-licitud i atenció per a fer bé alguna cosa». Per tant, l'autocura seria «l'atenció d'un i per un mateix».

Aquest concepte és una expressió molt utilitzada en infermeria. Des de 1860, amb Florence Nightingale, fins a 1986, amb Margaret Newman (Bengoa i altres, 2009), nombroses infermeres i teòriques de la infermeria han descrit com es pot millorar la salut en els pacients i han exposat diverses teories i models d'atenció sobre les cures en infermeria. Ens centrarem en la infermera i teòrica Dorotea Orem (2015), que va proposar la teoria general de la infermeria, constituïda per les tres teories següents (Esquema 2): $a$ ) Teoria de l'autocura; $b$ ) Teoria del dèficit d'autocura; i $c$ ) Teoria dels sistemes d'infermeria.

\subsubsection{L'autocura}

L'autocura és una activitat que l'individu aprèn i que està orientada cap a un objectiu. És una conducta que apareix en situacions concretes de la vida i que l'individu dirigeix cap a si mateix o cap a l'entorn per a regular els factors que afecten el seu propi desenvolupament i la seua activitat en benefici de la vida, la salut i el benestar (Orem, 1971).

El nou model de cures a pacients crònics a través de les autocures es planteja els objectius següents:

- Proposar un pla de cures pactat amb el pacient.

- Que el pacient assumisca la coresponsabilitat de definir els objectius que vol aconseguir juntament amb el seu equip de professionals metge-infermer (presa de decisions compartida).

- Adequar els serveis a l'evolució de les necessitats i demandes del ciutadà. 


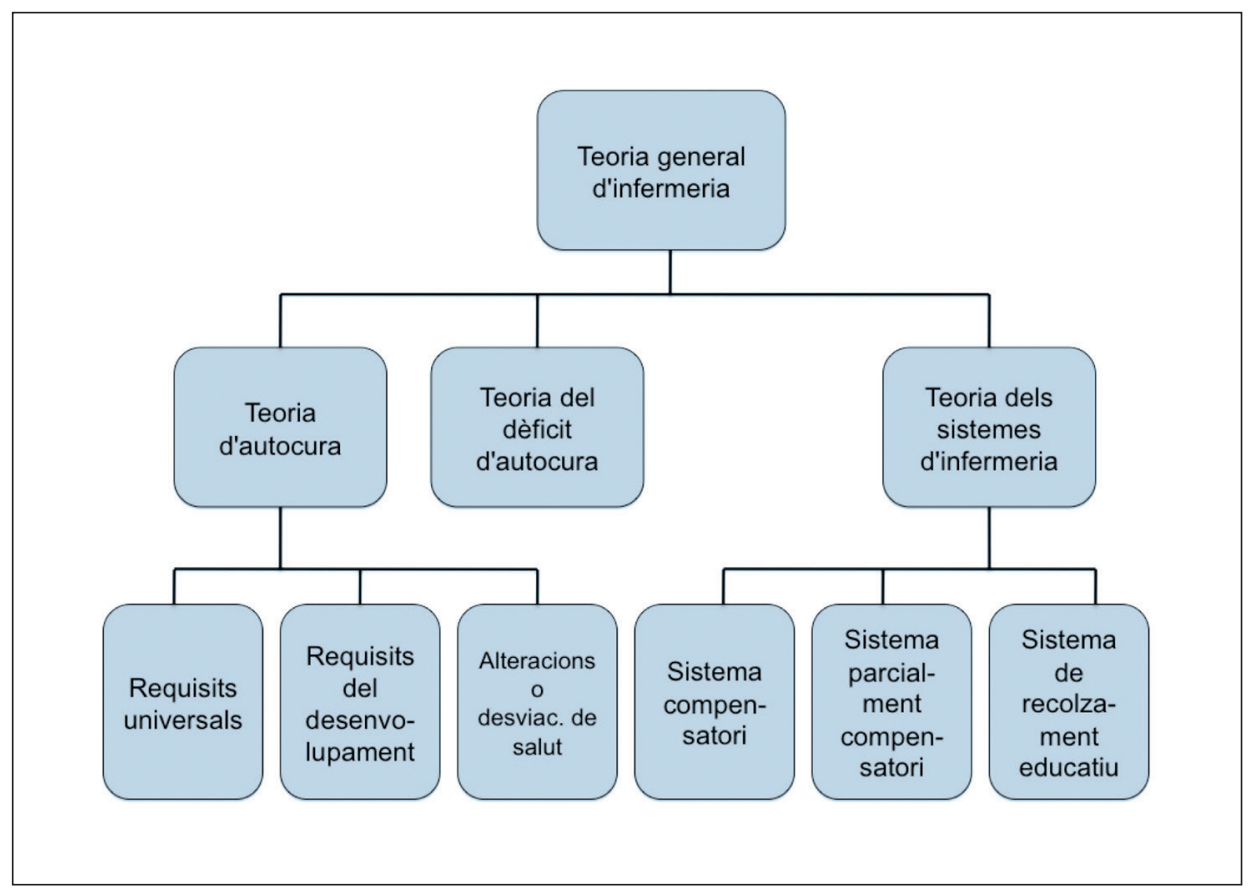

Esquema 2. Teoria de l'autocura segons Dorotea Orem (modificat d'Orem, 1971).

- Proposar estratègies per a potenciar l'autocura.

- Aconseguir que els ciutadans siguen proactius i ensenyar-los a identificar l'educació com una eina terapèutica.

\subsection{Educació terapèutica en el model de cronicitat}

L'educació terapèutica segons l'Organització Mundial de la Salut es defineix com el conjunt d'activitats educacionals essencials per a la gestió de les malalties cròniques, dutes a terme pels professionals de la salut formats en el camp de l'educació, creades per a ajudar el pacient o grups de pacients i/o familiars a realitzar el seu tractament i prevenir les complicacions evitables, alhora que es manté o millora la qualitat de vida (OMS, 1998 dins Ferrer i altres, 2012).

L'objectiu de l'educació terapèutica és ajudar el pacient a adquirir els recursos necessaris per a gestionar òptimament la seua vida amb una malaltia crònica. L'educació terapèutica del pacient ha demostrat la seua eficàcia en diverses malalties cròniques (asma, diabetis mellitus, malalties cardiovasculars, etc.).

L'educació terapèutica és part integrant del tractament. Què significa això? Vol dir que totes les parts del tractament, com ara fàrmacs, pla d'alimentació, exercici físic, prevenció i tractament de complicacions, requereixen un coneixement i, sobretot, un saber fer del pacient. 


\subsubsection{Objectius de l'educació terapèutica}

Els objectius de l'educació terapèutica són:

- Capacitar les persones amb malaltia crònica per a prendre decisions sobre la seua malaltia.

- Mantenir un control acceptable de tots els paràmetres clínics (tensió arterial, glucosa, pes, colesterol, etc.), així com d'altres en funció de la malaltia crònica.

- Augmentar l'adherència al tractament farmacològic i no farmacològic.

- Disminuir les complicacions.

- Augmentar la qualitat de vida.

Tot l'anterior implica que el pacient se senta responsable de la seua salut, aprenga a suportar la malaltia, adquirisca i mantinga hàbits saludables i reforce la seua autoestima.

\subsubsection{Components de l'educació terapèutica}

L'educació terapèutica es caracteritza per ser estructurada, ${ }^{2}$ comptar amb tres o més sessions educatives, tenir un seguiment mínim de sis mesos, incloure, com a mínim, un d'aquests factors: alimentació, exercici físic, tabac i alcohol, i comptar amb intervencions d'educació individual o grupal. Aquest tipus de tractament pedagògic del pacient per part del professional sanitari es pot aconseguir amb un canvi en l'educació sanitària tradicional (passiva/vertical) per una educació en autocures (proactiva/horitzontal).

\section{Pacient expert $o$ actiu}

El Programa Pacient Expert (Patient Education Research Center) actualment ubicat a la Facultat de Medicina de Stanford, dins del Departament de Medicina, va començar l'any 1979 a la Universitat de Stanford, Palo Alto, Califòrnia (EUA). La seua directora és la infermera i professora Kate Loring, que desenvolupa i avalua conjuntament amb el seu equip programes d'autocura tant en anglès com en espanyol (Smith i altres, 2015, Bruce i altres, 2007). ${ }^{3}$

\subsection{Recomanacions per a posar en marxa un curs de pacient actiu/expert}

Els diferents cursos dins del Programa Pacient Actiu/Expert són cursos d'autocura que ensenyen a autogestionar la malaltia, és a dir, ensenyen a pacients crònics a ser capaços d'entendre la seua malaltia, responsabilitzar-se de la seua salut i tenir control adequat de les distintes opcions de tractament.

\footnotetext{
${ }^{2}$ S'entén per educació estructurada per a pacients aquella que es proporciona mitjançant un programa planificat i progressiu, que és coherent amb els objectius planificats i pactats amb el pacient, que és flexible en el contingut, que cobreix les necessitats clíniques individuals i psicològiques i que és adaptable al nivell i context cultural.

${ }^{3}$ Es pot consultar el web a través de l'enllaç següent: $<$ http://patienteducation.stanford.edu/staff.html $>$ (consultat el 2 de gener de 2015).
} 
Quan reben el curs, una vegada formats i assessorats, seran capaços de liderar grups de pacients de forma eficaç, ja que han viscut les mateixes experiències i dificultats que la resta dels pacients del grup respecte a la malaltia crònica des del punt de vista físic, psicològic i social. A més, utilitzen el mateix llenguatge, fet que facilita la comprensió i l'empatia.

L'objectiu del programa és complementar la tasca dels professionals sanitaris (no substituir-la), ja que posa en mans dels pacients el coneixement suficient per a controlar millor la seua condició crònica i l'impacte que aquesta té en les seues vides i en la relació amb el seu entorn. Un exemple en la nostra comunitat de Programa Pacient Expert és el Programa de Rehabilitació Cardíaca Fase III que du a terme l'Institut Valencià del Cor (INSVACOR: <http://insvacor.es/rehab/>).

S'ofereixen cursos dirigits a qualsevol persona que patesca alguna malaltia crònica o a familiars o cuidadors d'aquestes persones. El curs es pot estructurar en sessions d'un dia a la setmana amb una durada d'una hora i mitja durant sis setmanes consecutives, tot i que la durada de les sessions pot variar. S'aconsella que no siguen més llargues d'una hora i mitja, ja que és un fet acceptat que a partir d'hora i mitja disminueix l'interès segons les tècniques de comunicació (Orem, 2015).

\section{Adequar els serveis a l'evolució de les necessitats i demandes del ciutadà}

Davant la nova situació plantejada, s'ha de caminar cap a un escenari d'atenció integrada per a persones amb processos crònics. Cal desenvolupar serveis sociosanitaris que oferesquen respostes a les necessitats i expectatives de la ciutadania, tot configurant un escenari en el qual s'oferesquen paral-lelament serveis per a persones que per les seues condicions sociosanitàries (malaltia crònica $i$ ancians que viuen sols) requeresquen prestacions de manera integrada, tant des del punt de vista sanitari com social. Aquests elements són, sens dubte, factors importants que determinaran un augment de la demanda d'aquests serveis.

L'evolució de la dependència juntament amb altres factors econòmics, socials i familiars del nostre país constitueixen factors de gran interès que han de ser analitzats. L'extensió i cobertura de serveis per a persones majors amb problemes de cronicitat, tant en l'àmbit sanitari com social, encara és baixa comparada amb altres països, i el nostre model d'atenció domiciliària, centrat bàsicament en la família, difícilment és sostenible en el temps.

En aquesta última dècada, en la literatura científica s'estan publicant treballs que presenten models on l'eix central ha estat la configuració d'escenaris de serveis integrats de salut. També la ciutadania demana participar més activament en la presa de decisions relacionades amb el seu procés de salut-malaltia.

Sense cap dubte, en tot aquest procés de desenvolupament de models orientats a l'atenció integrada del pacient crònic, les infermeres de família i els metges de família d'atenció primària han d'aportar un lideratge de primer ordre, especialment els professionals d'infermeria, ja que molts d'aquests pacients requereixen cures de qualitat i educació terapèutica per saber eixir-se'n de forma autònoma i adaptar-se a la seua condició de pacient crònic. 


\section{Conclusions}

Les persones amb malaltia crònica han d'estar capacitades en el procés d'autocures estructurades per a obtenir un millor control i més autonomia (Burgos-Martínez, 2014, Bruce i altres, 2007). Potenciar l'autocura ha de ser una iniciativa multidisciplinària basada en la collaboració pacient-professional a través del treball en equip. L'autocura condueix a la coresponsabilització del pacient per a establir objectius consensuats i un pla de cures per aconseguir un millor control de la malaltia i una qualitat de vida millor. La participació en tallers per a pacients, familiars i cuidadors, presencials o en línia (fòrums estructurats i avaluats per professionals), pot facilitar aquest procés (Johnson i altres, 2011, Lorig i altres, 2008).

Finalment, per a realitzar una bona planificació sanitària, cal conèixer les expectatives de la ciutadania. Aquesta transformació del sistema cap a una gestió millorada de la cronicitat és alhora una oportunitat per a obrir un debat organitzat sobre la necessitat de prioritzar les prestacions i explicar millor a la ciutadania els límits d'aquestes i del sistema sanitari. Les expectatives dels ciutadans continuen creixent i per això és necessari potenciar les associacions de pacients i associacions ciutadanes en la comunitat per a facilitar la integració de les cures als pacients crònics en la comunitat on viuen.

\section{BIBLIOGRAFIA}

BENGOA, R. i R. NUÑo (2009): Curar y cuidar. Innovación en la gestión de enfermedades crónicas: una guía práctica para avanzar, Barcelona, Elservier-Masson.

BRUCE, B. i altres (2007): «Participation in patient self-management programs», Arthritis Rheum, 57 , 851-854.

FERrer, C. i altres (2012): Estrategia para el abordaje de la cronicidad en el Sistema Nacional de Salud, Madrid, Ministerio de Sanidad, <http://www.msps.es/organizacion/sns/planCalidadSNS/pdf/ ESTRATEGIA_ABORDAJE_CRONICIDAD.pdf> (Consulta: 2-2-2015).

GonzÁlez, V. i altres (2002): Tomando control de su salud, Boulder, Bull Publishing, <http://www. bullpub.com/salud.html> (Consulta: 2-2-2015).

Johnson, V.B. i K. LoRIg (2011): «The internet diabetes self-management workshop for American Indians and Alaska Natives», Health Promotion Practice, 12, 261-270.

LorIG, K. i altres (2008a): «Spanish diabetes self-management with and without automated telephone reinforcement: two randomized trials», Diabetes Care, 31, 408-414.

LORIG, K. i altres (2008b): «The internet-based arthritis self-management program: a one-year randomized trial for patients with arthritis or fibromyalgia», Arthritis Rheumatology, 59, 1009-1017.

LoRIG, K. i altres (2010): «Online diabetes self-management program: a randomized study», Diabetes Care, 33, 1275-1281.

Orem, D. (2015 [1971]): Teoría del autocuidado, <http://es.wikiversity.org/wiki/Autocuidado> (Consulta: 2-2-2015).

RichARDSON, J. i altres (2014): «Self-management interventions for chronic disease: a systematic scoping review», Clinical Rehabilitation, novembre, 28 (11),1067-1077.

Sмiтн, M.L. i altres (2015a): «Workshop characteristics related to chronic disease self-management education program attendance», Frontiers in Public Health, 3, 19.

Sмiтн, M.L. i altres (2015b): «Chronic disease self-management program in the workplace: opportunities for health improvement», Frontiers in Public Health, 2, 179. 


\section{BIONOTES}

\section{Concepción Carratalá}

$\mathrm{BN}, \mathrm{MsC}, \mathrm{PhD}$. Infermera. Presidenta de la Societat Científica Espanyola d'Infermeria. Màster en Salut Pública i Doctora per la Universitat Miguel Hernández. Experta en cronicitat. Professora associada del Departament de Medicina Clínica de la Universitat Miguel Hernández.

\section{Domingo Orozco}

MD, PhD. Especialista en Medicina de família. President de la Comissió Nacional de l'especialitat de Medicina de Família. Co-coordinador de l'estratègia d'abordatge de la Cronicitat del Ministeri de Sanitat, Política Social i Igualtat. Professor associat del Departament de Medicina Clínica de la Universitat Miguel Hernández. 